\title{
QUANTIFICAÇÃO DA EMISSÃO DE GASES ORIUNDOS DA SUINOCULTURA
}

\section{Pedro Hurtado de Mendoza Borges ${ }^{1}$, Pedro Hurtado de Mendoza Morais ${ }^{2}$, Zaíra Morais dos Santos Hurtado de Mendoza ${ }^{3}$.}

${ }^{1}$ Prof.Dr. do Departamento de Solos e Engenharia Rural. Universidade Federal de Mato Grosso (UFMT). Cuiabá, Mato Grosso, Brasil. (pedrohmborges14@gmail.com)

${ }^{2}$ Acadêmico do Curso de Agronomia da Universidade Federal de Mato Grosso (UFMT). Cuiabá, Mato Grosso, Brasil.

${ }^{3}$ Prof $^{a} \mathrm{Dr}^{\mathrm{a}}$ do Departamento de Engenharia Florestal. Universidade Federal de Mato Grosso (UFMT). Cuiabá, Mato Grosso, Brasil.

Recebido em: 04/10/2019 - Aprovado em: 30/11/2019 - Publicado em: 15/12/2019 DOI: 10.18677/EnciBio 2019B61

A concentração de gases poluentes acima dos níveis permissíveis, principalmente no interior das instalações, pode trazer inúmeros prejuízos para a suinocultura. Dentre os principais gases que reduzem a qualidade do ar nessas instalações podemos citar o metano $\left(\mathrm{CH}_{4}\right)$, o dióxido de carbono $\left(\mathrm{CO}_{2}\right)$, o monóxido de carbono (CO) e a amônia $\left(\mathrm{NH}_{3}\right)$. As emissões desses gases podem ser influenciadas por diversos fatores como o sistema de criação, a raça e as características construtivas das instalações e, ainda, podem aumentar de forma significativa devido ao manejo inadequado dos dejetos. Assim, a estimativa das concentrações dos referidos gases é de suma importância para dimensionar ou melhorar o sistema de ventilação e as características construtivas nessas instalações. Portanto, este trabalho teve como objetivo quantificar as emissões dos gases metano, dióxido e monóxido de carbono e amônia em duas instalações suinícolas. A coleta foi realizada durante a primeira quinzena do mês de setembro de 2019. A concentração dos gases foi determinada com um dispositivo desenvolvido no Laboratório de Automação Agropecuária da Faculdade de Agronomia e Zootecnia da Universidade Federal de Mato Grosso. Os dados foram importados pela planilha eletrônica EXCEL e, em seguida, realizou-se a análise estatística no Programa R. Concluiu-se que, a medição das concentrações dos gases, em função do tipo de instalação, apresentou-se como uma ferramenta útil para auxiliar na avaliação do ambiente, podendo subsidiar melhorias construtivas nos galpões. A metodologia adotada mostrou adequada eficiência para monitorar o ambiente interno das unidades suinícolas.

PALAVRAS-CHAVE: Ambiência, efeito estufa, qualidade do ar.

\section{QUANTIFICATION OF THE GAS EMISSION FROM SWINE FARMING}

\section{ABSTRACT}

The concentration of pollutant gases above the allowable levels, especially inside the facilities, can bring numerous losses to swine farming. The main gases that reduce air quality in these installations include methane $\left(\mathrm{CH}_{4}\right)$, carbon dioxide $\left(\mathrm{CO}_{2}\right)$, carbon 
monoxide (CO) and ammonia $\left(\mathrm{NH}_{3}\right)$. Emissions of these gases can be influenced by several factors such as the rearing system, the breed and the constructive characteristics of the installations and can also increase significantly due to improper waste management. Thus, the estimation of the concentrations of these gases is of paramount importance to dimension or improve the ventilation system and the constructive characteristics in these installations. Therefore, this work aimed to quantify the emissions of methane, dioxide and carbon monoxide and ammonia gases in two swine farms. Collection was performed during the first half of September 2019. The gas concentration was determined with a device developed at the Agricultural Automation Laboratory of the Faculty of Agronomy and Zootechnic of the Federal University of Mato Grosso. The data were imported by the spreadsheet EXCEL and then performed the statistical analysis in Program R. It was concluded that the measurement of gas concentrations, depending on the type of installation, was a useful tool to assist in the assessment of the environment and could support constructive improvements in the sheds. The adopted methodology showed adequate efficiency to monitoring the internal environment of the swine units.

KEYWORDS: Greenhouse effect, air quality, ambience.

\section{INTRODUÇÃO}

A suinocultura é uma atividade rentável que contribui para o Produto Interno Bruto (PIB) agropecuário, sendo assim, essa prática é de extrema importância para a economia do nosso País. O Brasil é o quarto maior produtor de carne suína no mundo, com 3.759 milhões de toneladas produzidas, que corresponde a $3 \%$ da produção mundial. Desse total, são exportados somente $18,5 \%$ ficando no mercado interno $81,5 \%$. No contexto nacional, a região sul lidera a produção, sendo o Estado de Santa Catariana o maior produtor, gerando 1,5 milhão de toneladas, o que representa $28,38 \%$ da produção (ABPA, 2018).

Por outro lado, com o aumento na produção de suínos haverá também uma maior quantidade de dejetos. Os dejetos oriundos da suinocultura são formados pelas fezes, urina, resíduos de ração e água excedente proveniente dos bebedouros e da higienização das instalações. O manejo inadequado desses dejetos pode gerar diversos problemas, tanto no interior dos galpões, quanto nas suas proximidades, uma vez que liberam gases tóxicos, o que contribui para a contaminação e poluição do maio ambiente. Os impactos ambientais causados pelo manejo inadequado dos dejetos suinícolas podem causar severos danos, como a emissão de odores, gases nocivos, riscos de poluição em mananciais de água superficiais e subterrâneas, bem como no próprio solo (CARDOSO et al., 2015; DAMACENO et al., 2017).

A concentração de gases poluentes acima dos níveis permissíveis, principalmente no interior das instalações, pode trazer prejuízos para a suinocultura. Dentre os principais gases que reduzem a qualidade do ar nessas instalações citase o metano $\left(\mathrm{CH}_{4}\right)$, o dióxido de carbono $\left(\mathrm{CO}_{2}\right)$, o monóxido de carbono (CO) e a amônia $\left(\mathrm{NH}_{3}\right)$. Os dois primeiros pertencem ao grupo dos gases do efeito estufa. Já, o efeito do monóxido é reduzido após as primeiras semanas de vida e, geralmente, não causa problemas. O gás amônia origina-se a partir da decomposição microbiana dos dejetos e interfere negativamente no desempenho produtivo dos animais, além de provocar efeitos adversos nos seres humanos provocando irritações nos olhos e na pele (ITO et al., 2016).

As emissões dos referidos gases são influenciadas pelo sistema de criação, raça e as características construtivas das instalações e podem aumentar de forma 
significativa devido ao manejo inadequado dos dejetos (NUNES; MIRANDA, 2013). Assim, o conhecimento dos níveis de concentração desses gases é de suma importância para dimensionar ou aprimorar o sistema de ventilação e as características construtivas nessas instalações. Portanto, este trabalho teve como objetivo quantificar a concentração dos gases metano, amônia, dióxido e monóxido de carbono em instalações suinícolas visando melhorar esse ambiente e o seu entorno.

\section{MATERIAL E MÉTODOS}

A pesquisa foi desenvolvida no setor de suínos da Fazenda Experimental da Faculdade de Agronomia e Zootecnia, Universidade Federal de Mato Grosso, localizada no município Santo Antônio de Leverger-MT. As coordenadas geográficas foram definidas pela latitude de $-15,7833^{\circ}$ e longitude de $-56,0667^{\circ}$, sendo a altitude de $140 \mathrm{~m}$. A região apresenta clima tropical, classificado como Aw (PEEL et al., 2007). A temperatura média anual e a pluviosidade média anual são de $26,1^{\circ} \mathrm{C}$ e $1267 \mathrm{~mm}$, respectivamente (INMET, 2019).

Devido à disponibilidade de animais, foram selecionados apenas dois galpões para realizar este estudo, correspondendo às fases de reprodução e terminação com exemplares da raça Landrace. Na instalação para a fase de reprodução alocaram-se 14 matrizes em baias individuais e dois cachaços com peso médio variando entre 180 e $200 \mathrm{Kg}$. O galpão tinha como principais dimensões $40 \mathrm{~m}$ de comprimento, 12 $\mathrm{m}$ de largura e 3,2 m de altura, sendo que a área útil das baias foi de 9,5 m². Já, na instalação para a fase de terminação colocaram-se 42 animais, utilizando-se baias coletivas com três animais, cujo peso variou entre 80 e $100 \mathrm{Kg}$. Esse galpão mediu $14 \mathrm{~m}$ de comprimento, $10 \mathrm{~m}$ de largura e $5,5 \mathrm{~m}$ de altura. As duas instalações tinham telhado de cerâmica com parâmetros mínimos disponíveis para o conforto ambiental dos animais, tais como altura, ventilação e luminosidade, sendo estes dois últimos quesitos atendidos de forma natural e artificial.

A coleta foi realizada diariamente, no período de 24 horas, durante a primeira quinzena do mês de setembro de 2019. A concentração dos gases metano $\left(\mathrm{CH}_{4}\right)$, dióxido de carbono $\left(\mathrm{CO}_{2}\right)$, monóxido de carbono (CO) e amônia $\left(\mathrm{NH}_{3}\right)$ foi determinada com o dispositivo desenvolvido no Laboratório de Automação Agropecuária da Faculdade de Agronomia e Zootecnia da Universidade Federal de Mato Grosso. Esse dispositivo está composto basicamente pelo microcontrolador Arduino Uno, quatro sensores para gases (MQ-02, MQ-04, MQ-07 e MQ-135), um sensor de temperatura e umidade (DTH22), um módulo RTC DS3231 para o controle da data e hora e um módulo SD para armazenar os dados no cartão de memória com formato de arquivo texto.

Os dados coletados foram importados pela planilha eletrônica EXCEL para facilitar a transformação dos valores lidos pelos sensores de gases em bits para a unidade de medida partículas por milhão (ppm), usando-se funções potenciais. Em seguida, utilizou-se o programa R, desenvolvido por R Core Team, Versão 3.5.0 de 2018, para determinar as principais estatísticas descritivas das concentrações dos quatro gases e das variáveis microclimáticas temperatura e umidade que foram obtidas em cada galpão e, também, para elaborar os respectivos diagramas de caixa ("box plot"). Com auxílio do mencionado recurso computacional, foi verificada a normalidade dos dados dessas variáveis, aplicando-se o teste Shapiro-Wilk e foram comparadas as médias correspondentes a cada instalação suinícola, conforme o teste t (Student). 


\section{RESULTADOS E DISCUSSÃO}

$\mathrm{Na}$ Tabela 1 apresentam-se as principais estatísticas descritivas referentes à concentração de cada gás e às variáveis microclimáticas temperatura e umidade, correspondentes a cada instalação suinícola. Conforme essa Tabela, os valores das concentrações para os quatro gases evidenciaram pouca variabilidade, dado pelos baixos parâmetros estatísticos desvio padrão, intervalo de confiança e coeficiente de variação, sendo todos inferiores a 10 . Entretanto, para as variáveis microclimáticas, os mencionados parâmetros foram elevados. Isso concorda com o esperado, pois a temperatura e umidade variam ao longo do dia e podem ser influenciadas de forma determinante pelas características construtivas da instalação, como tipo de telhado e altura, dentre outras.

TABELA 1. Estatísticas descritivas dos gases e variáveis microclimáticas, conforme a instalação de coleta.

\begin{tabular}{llrrr}
\hline \multicolumn{1}{c}{ Variável e unidade } & Instalação & \multicolumn{1}{c}{ Média ${ }^{ \pm D P}$} & IC $_{95 \%}$ & CV (\%) \\
\hline \multirow{2}{*}{ Metano (ppm) } & Reprodução & $8,52 \pm 0,737$ & 0,054 & 8,65 \\
& Terminação & $9,86 \pm 0,846$ & 0,062 & 8,59 \\
\multirow{2}{*}{ Monóxido de carbono (ppm) } & Reprodução & $0,37 \pm 0,019$ & 0,002 & 5,07 \\
& Terminação & $0,42 \pm 0,019$ & 0,001 & 4,43 \\
\multirow{2}{*}{ Dióxido de carbono (ppm) } & Reprodução & $378,09 \pm 27,80$ & 2,031 & 7,35 \\
\multirow{2}{*}{ Amônia (ppm) } & Terminação & $315,06 \pm 21,84$ & 1,595 & 6,93 \\
& Reprodução & $7,86 \pm 0,765$ & 0,056 & 9,73 \\
\multirow{2}{*}{ Temperatura $\left({ }^{\circ} \mathrm{C}\right)$} & Terminação & $7,12 \pm 0,628$ & 0,046 & 8,82 \\
\multirow{2}{*}{ Umidade $(\%)$} & Reprodução & $29,51 \pm 5,201$ & 0,380 & 17,61 \\
& Terminação & $27,36 \pm 5,443$ & 0,397 & 19,87 \\
& Reprodução & $59,27 \pm 19,28$ & 1,408 & 32,53 \\
& Terminação & $59,23 \pm 18,70$ & 1,366 & 31,58 \\
\hline
\end{tabular}

DP: Desvio padrão; IC $95 \%$ : Intervalo de confiança para 95\%; CV: Coeficiente de variação;

Nessa Tabela constata-se que, as concentrações dos gases metano $\left(\mathrm{CH}_{4}\right)$ e monóxido de carbono (CO) foram superiores na instalação de terminação, enquanto que para as concentrações de dióxido de carbono $\left(\mathrm{CO}_{2}\right)$ e amônia $\left(\mathrm{NH}_{3}\right)$ os maiores valores foram estimados na instalação de reprodução. Na própria Tabela 1 infere-se que a temperatura do ar foi em torno de $2,2^{\circ} \mathrm{C}$ superior no galpão de reprodução, em relação à instalação de terminação. Deve-se ressaltar que, o valor médio registrado no galpão de terminação encontra-se acima do intervalo entre 18 e $21^{\circ} \mathrm{C}$, sugerido para esta fase (NFACC, 2014). Porém, para a variável microclimática umidade do ar, o valor médio estimado nas duas instalações foi semelhante.

O diagrama de caixa ("box plot") para a concentração do gás metano pode ser observado na Figura 1. Verifica-se que, em torno de $75 \%$ dos valores coletados na instalação de reprodução ficaram abaixo de 9 ppm, porém, para essa quantidade de medições no galpão de terminação, o valor foi de aproximadamente 10,5 ppm. Notase, ainda, que nessa instalação a distância interquartil foi superior, indicando maior variabilidade dos dados. Contudo, os valores das concentrações de metano $\left(\mathrm{CH}_{4}\right)$ determinados em ambos os galpões foram inferiores aos estimados por Robin (2010 e Guingand et al. (2011). 


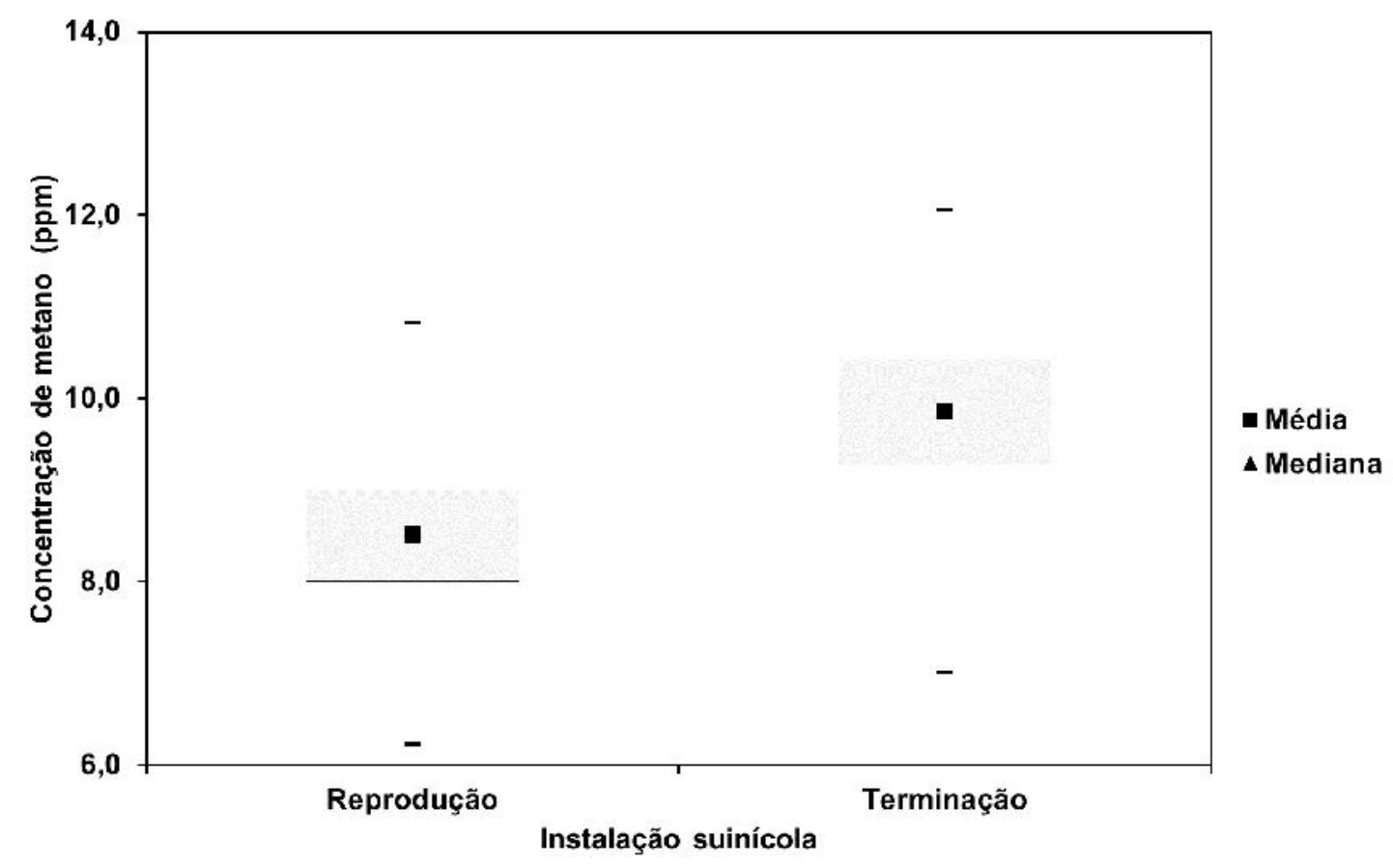

FIGURA 1. Diagrama de caixa ("box plot") para a concentração do gás metano em cada instalação suinícola.

Na Figura 2 apresenta-se o diagrama de caixa para a concentração do gás monóxido de carbono. Nessa Figura, nota-se que $75 \%$ das concentrações estimadas na instalação de reprodução foram inferiores a 0,38 ppm. Porém, essa proporção no galpão de terminação atingiu aproximadamente $0,44 \mathrm{ppm}$. Os dados obtidos nessas instalações evidenciaram pouca variabilidade, indicado pela pequena distância entre o primeiro e terceiro quartil. Deve-se ressaltar, ainda, que as concentrações do gás monóxido de carbono (CO), observadas nas duas instalações, foram muito inferiores aos limites máximos recomendados para humanos até 50 ppm e para suínos entre 50 e 100 ppm (ABCS, 2014).

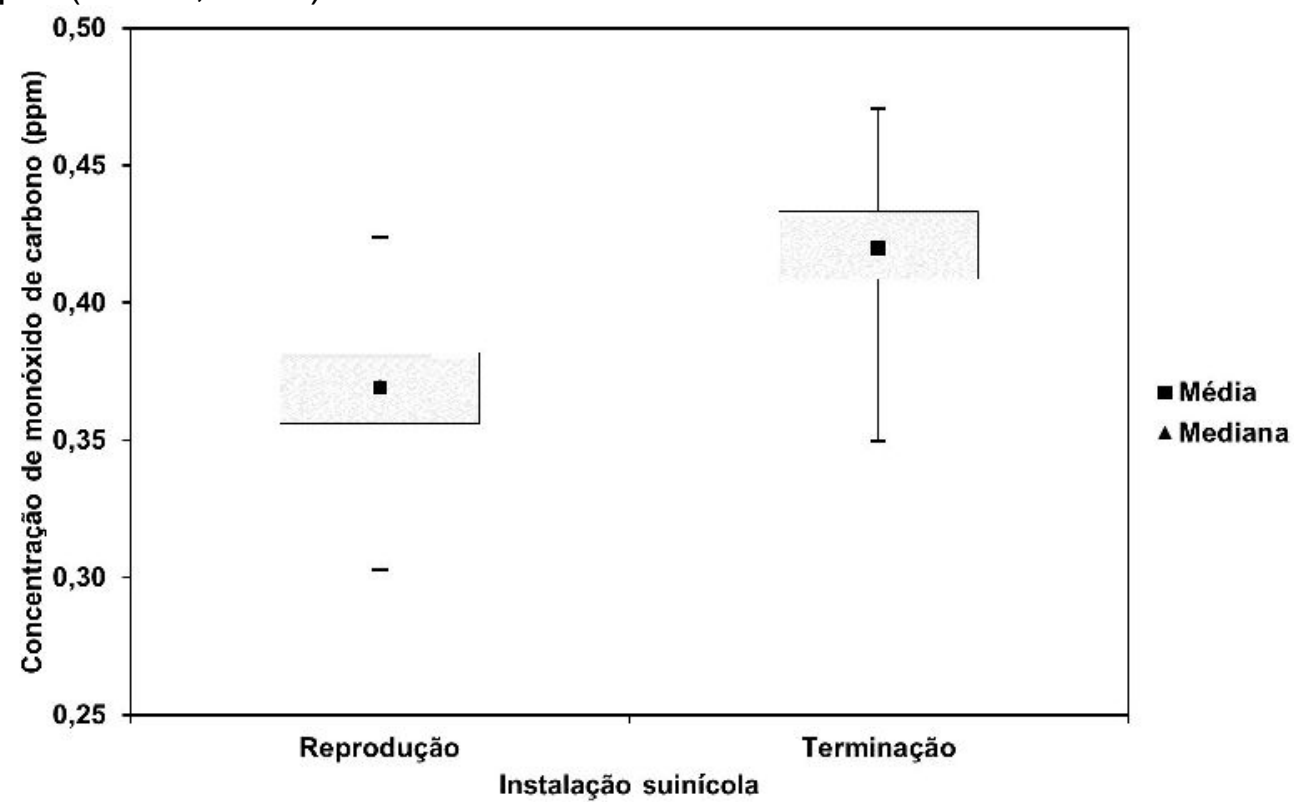

FIGURA 2. Diagrama de caixa ("box plot") para a concentração do gás monóxido de carbono em cada instalação suinícola. 
Para ilustrar o comportamento dos valores da concentração do gás dióxido de carbono foi elaborado o diagrama de caixa da Figura 3. De acordo com essa Figura, deduz-se que a metade das leituras registradas no galpão de reprodução variaram entre 360 e 395 ppm, entretanto, na instalação de terminação entre 300 e 325 ppm. Também, nota-se que a variabilidade dos dados foi maior no galpão de reprodução, pois a distância interquartil foi superior. Não obstante, as concentrações do gás dióxido de carbono $\left(\mathrm{CO}_{2}\right)$, determinadas nas referidas instalações, foram inferiores aos limites máximos sugeridos para humanos e suínos, respectivamente, de 1540 e 2500 ppm (ABCS, 2014).

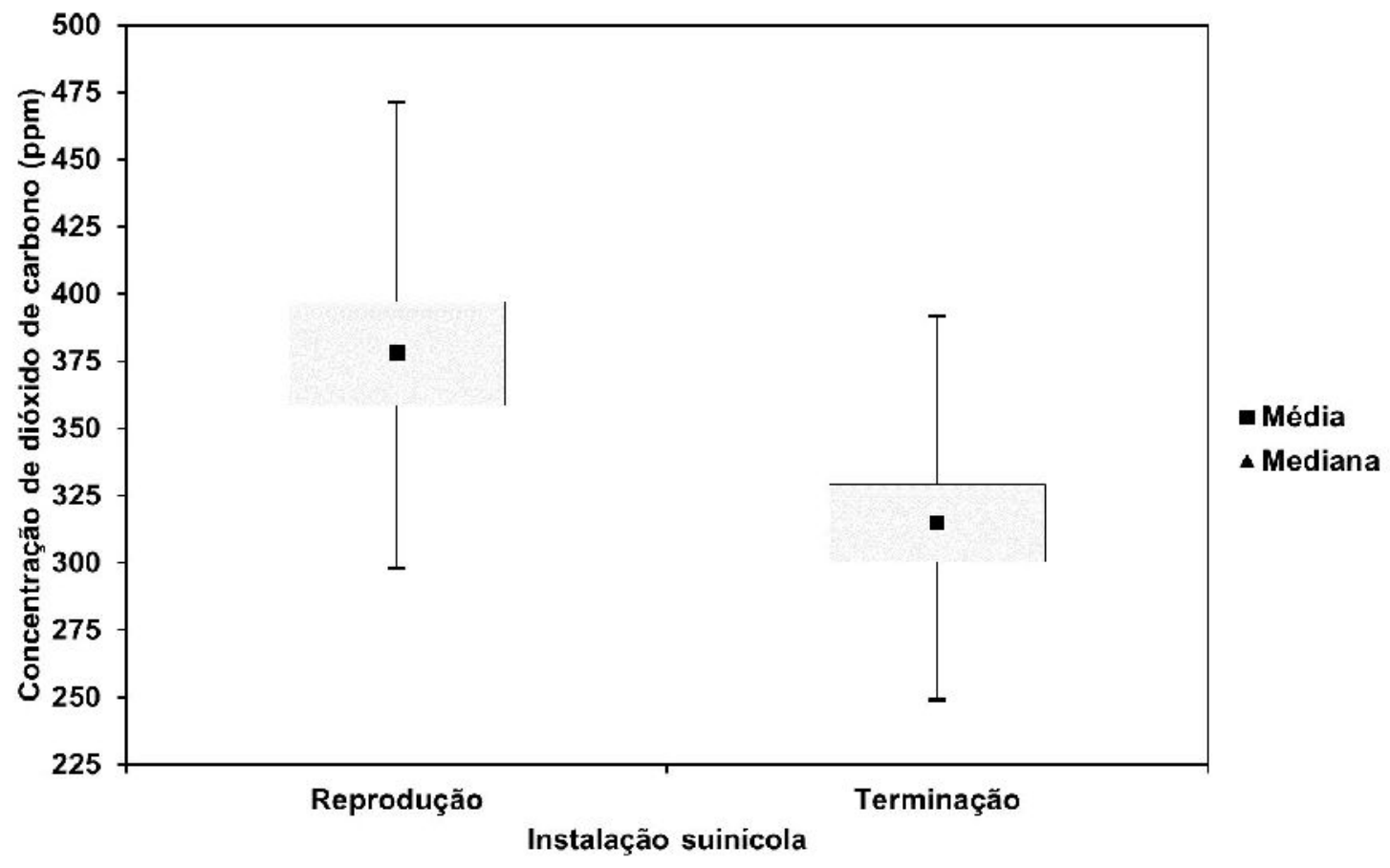

FIGURA 3. Diagrama de caixa ("box plot") para a concentração do gás dióxido de carbono em cada instalação suinícola.

O diagrama de caixa para a concentração de amônia encontra-se na Figura 4. Nessa Figura, constata-se que $50 \%$ dos dados coletados na instalação para a fase de reprodução ficaram entre 7,5 e 8,2 ppm, porém, no galpão de terminação entre 6,5 e 7,6 ppm. Pela própria Figura deduz-se que, a variabilidade dos dados foi maior na instalação de reprodução, evidenciado pela superior distância interquartil. Nessa instalação, o referido intervalo de concentrações do gás amônia $\left(\mathrm{NH}_{3}\right)$ está acima do limite recomendado para humanos de 7 ppm (ABCS, 2014). Já, no outro galpão encontram-se muito próximos a esse limite. Com base nestes resultados, sugere-se o uso de máscaras para os funcionários, se caso for necessário permanecer durante longos períodos nessas instalações. As concentrações de amônia determinadas em ambas as unidades não oferecem perigo aos animais, pois o limite permissível varia entre 11 e 25 ppm (ABCS, 2014). 


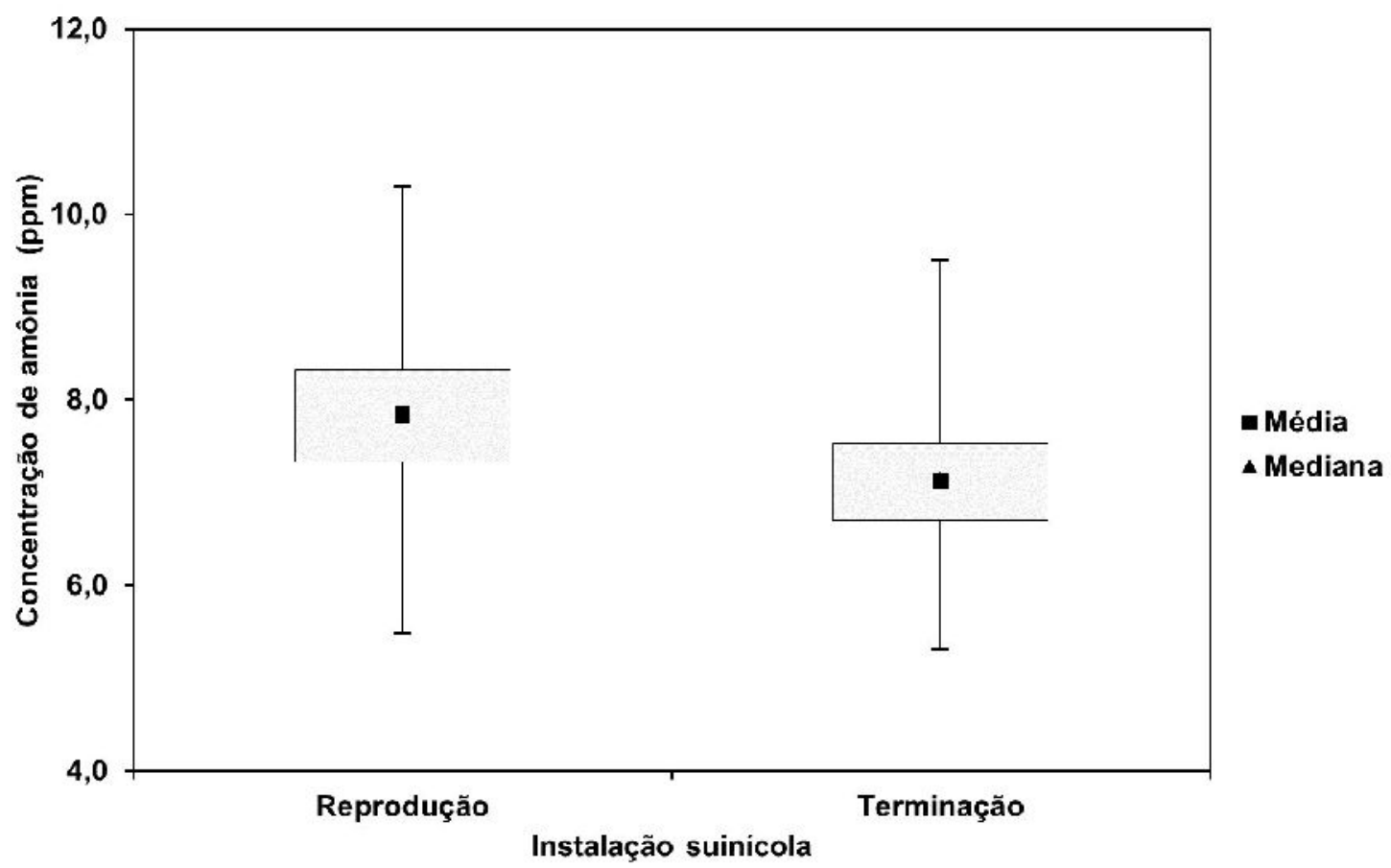

FIGURA 4. Diagrama de caixa ("box plot") para a concentração do gás amônia em cada instalação suinícola.

No diagrama de caixa da Figura 5 representa-se a temperatura do ar. Nessa Figura, verifica-se que $75 \%$ dos valores de temperatura estimados na instalação de reprodução oscilaram entre 25,5 e $34^{\circ} \mathrm{C}$, entretanto, para essa proporção no galpão de terminação entre 23 e $33^{\circ} \mathrm{C}$. De acordo com a distância interquartil, constata-se que houve ampla variabilidade da temperatura do ar para as duas unidades, sendo maior na instalação de terminação. Os valores de temperatura determinados para essa instalação foram semelhantes aos obtidos por Santos et al. (2018). Contudo, foram superiores a $18^{\circ} \mathrm{C}$, valor recomendado como ideal para suínos em terminação (NFACC, 2014).

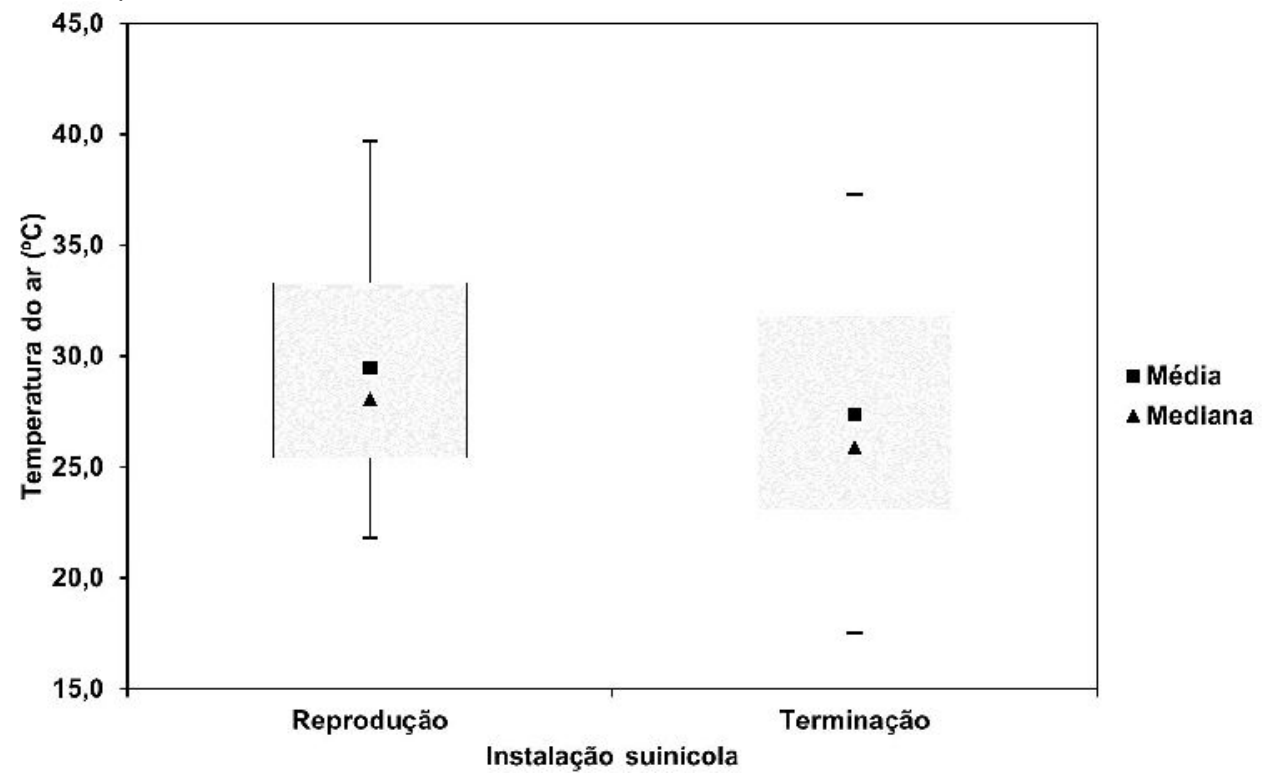

FIGURA 5. Diagrama de caixa ("box plot") para a temperatura do ar em cada instalação suinícola. 
Para observar o comportamento dos valores da umidade do ar foi elaborado o diagrama de caixa da Figura 6 . De acordo com essa Figura, deduz-se que a metade das leituras registradas nas duas unidades oscilaram, aproximadamente, entre $45 \mathrm{e}$ $75 \%$, evidenciando-se uma tendência semelhante. Os valores obtidos neste estudo foram superiores aos determinados por Santos et al. (2018). Assim, constata-se que a umidade do ar registrada nas instalações da presente pesquisa foi adequada, pois variou no intervalo ideal de conforto entre 50 e 70\% (ABCS, 2014; NFACC, 2014).

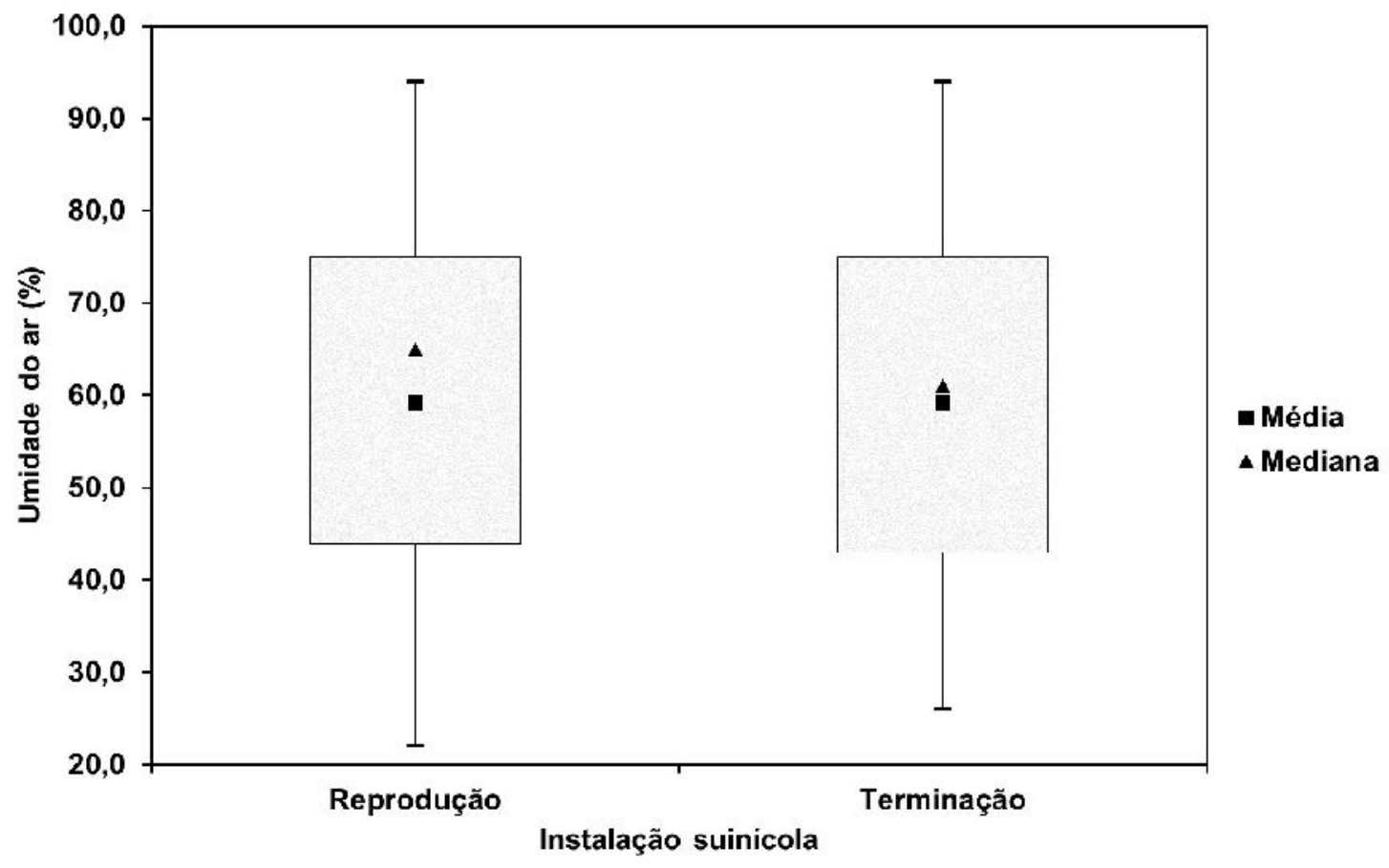

FIGURA 6. Diagrama de caixa ("box plot") para a umidade do ar em cada instalação suinícola.

A Tabela 2 contém os valores da estatística e probabilidade dos testes de normalidade e para a comparação de médias, aplicados às variáveis avaliadas em cada instalação suinícola. Nessa Tabela, pode-se constatar que somente os valores da concentração dos gases metano $\left(\mathrm{CH}_{4}\right)$, dióxido de carbono $\left(\mathrm{CO}_{2}\right)$ e amônia $\left(\mathrm{NH}_{3}\right)$ apresentaram normalidade, segundo o teste de Shapiro-Wilk. Para o gás monóxido de carbono (CO) e para as variáveis microclimáticas temperatura e umidade não foi confirmada a normalidade dos dados, conforme esse teste (Tabela 2). Apesar disso, o teste $t$ (Student) é robusto para tamanhos de amostras superiores a 30 e, portanto, a normalidade não é pré-requisito fundamental para ser aplicado, como mostram os estudos realizados por Chantarangsi et al. (2015), Nascimento et al. (2015), Le Boedec (2016), Miot (2017).

TABELA 2. Valores da estatística e probabilidade dos testes aplicados às variáveis avaliadas em cada instalação suinícola.

\begin{tabular}{llcccc}
\hline \multirow{2}{*}{ Variável } & \multirow{2}{*}{ Instalação } & \multicolumn{2}{c}{ Shapiro-Wilk } & \multicolumn{2}{c}{ Student } \\
\cline { 3 - 6 } & Reprodução & 0,9934 & Prob. & Estat. & Prob. \\
\hline \multirow{2}{*}{ Metano } & Terminação & 0,9980 & 0,5843 & 32,012 & 0,0002 \\
Monóxido de carbono & Reprodução & 0,9735 & 0,0003 & 51,527 & 0,0002
\end{tabular}




\begin{tabular}{llllll} 
& Terminação & 0,9706 & 0,0007 & & \\
Dióxido de carbono & Reprodução & 0,9972 & 0,2636 & 47,835 & 0,0003 \\
& Terminação & 0,9973 & 0,2843 & & \\
Amônia & Reprodução & 0,9985 & 0,7854 & 20,103 & 0,0002 \\
\multirow{2}{*}{ Temperatura } & Terminação & 0,9977 & 0,4448 & & \\
\multirow{2}{*}{ Umidade } & Reprodução & 0,9279 & 0,0002 & 7,668 & 0,0003 \\
& Terminação & 0,9294 & 0,0002 & & \\
& Reprodução & 0,9588 & 0,0003 & 0,037 & 0 \\
& Terminação & 0,9701 \\
\hline
\end{tabular}

Estat.: Valor da estatística do teste; Prob.: Valor da probabilidade correspondente ao resultado do teste.

Também, na Tabela 2 são apresentados os resultados do teste $t$ (Student) ao comparar as médias das concentrações dos quatro gases, bem como das variáveis microclimáticas temperatura e umidade, em função do tipo de instalação suinícola. Pode-se confirmar que somente a umidade não foi influenciada pelas características construtivas do galpão (altura do telhado e das paredes laterais), número e peso dos animais (Tabela 2). Isso concorda com o esperado, pois o número e peso dos animais interfere no volume das fezes e estas pela sua vez na emissão de gases poluentes. Por outro lado, a altura da instalação pode facilitar a ventilação e consequentemente a diminuição da temperatura. Já, a umidade do ar é mais difícil de reduzir de forma natural. Porém, alternativas como a sugerida por Borges et al. (2018) poderia ser uma solução útil e prática para manter as variáveis analisadas dentro dos limites de conforto ambiental recomendados para os trabalhadores e os animais.

\section{CONCLUSÃO}

A umidade do ar não foi influenciada pelas características construtivas das instalações e pela fase de criação dos animais. Já, as concentrações dos gases e a temperatura do ar evidenciaram dependência desses fatores.

A medição das concentrações dos gases e das variáveis microclimáticas, em função do tipo de instalação apresentou-se como uma ferramenta útil, para auxiliar na avaliação do ambiente, podendo subsidiar melhorias construtivas nos galpões.

A metodologia adotada mostrou adequada eficiência para o monitoramento do ambiente interno das unidades suinícolas, tendo como base os valores de referência dos gases tóxicos e das variáveis microclimáticas.

\section{REFERÊNCIAS}

ABCS - Associação Brasileira dos Criadores de Suínos. Produção de suínos: Teoria e Prática. Editora: Integral, Brasília-DF, 849p. 2014.

ABPA - Associação Brasileira de Proteína Animal . Estatísticas. 2018, Disponível

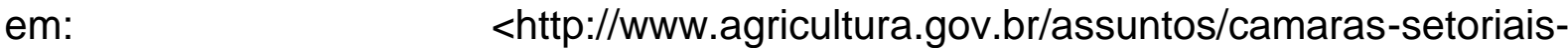
tematicas/documentos/camaras-setoriais/aves-e-suinos/2018/36a-ro/abpa-avesovos-e-suinos.pdf>

BORGES, P. H. M.; MENDOZA, Z. M. S. H.; MORAIS, P. H. M.; SANTOS, R. L. Sistema Automatizado de Baixo Custo para Produtores Rurais: Controle e 
monitoramento do ambiente térmico na suinocultura. Revista RECoDAF, Tupã, SP, v. 4, n.2, p. 177-199. 2018. Disponível em:

<http://codaf.tupa.unesp.br:8082/index.php/recodaf/article/view/79/165>

CARDOSO, B. F.; OYAMADA, G. C.; SILVA, C. M. Produção, Tratamento e Uso dos Dejetos Suínos no Brasil. Desenvolvimento em Questão, Editora Unijuí, v. 13, n. 32, p. 127-145, out./dez. 2015. Disponível em:

$<$ https://www.revistas.unijui.edu.br/index.php/desenvolvimentoemquestao/article/view /3159>. doi: 10.21527/2237-6453.2015.32.127-145

CHANTARANGSI, W.; LIU, W.; BRETZ, F.; KIATSUPAIBUL, S.; HAYTER, A. J.; WAN, F. Normal probability plots with confidence. Biometrical Journal. v. 57; n. 1, p. 52-63, 2015. Disponível em: $<$ https://onlinelibrary.wiley.com/doi/epdf/10.1002/bimj.201300244>.

doi: 10.1002/bimj.201300244

DAMACENO, F. M.; HALMEMAN, M. C. R.; GONÇALVES, M. S.; MEDEIROS, F. V. Aproveitamento agronômico e energético de dejeções suinícolas: Estudo de caso com análise econômico-financeira. Revista Agro@mbiente On-line, v. 11, n. 2, p. 174-180, 2017. Disponível em: <https://revista.ufrr.br/agroambiente/article/view/3963/2271> doi: 10.18227/1982-8470ragro.v11i2.3963

GUINGAND, N.; LAGADEC, S.; ROBIN, P.; HASSOUNA, M. Mise au point d'une méthode de mesure simplifiée des émissions d'ammoniac et des gaz à effet de serre des bâtiments d'élevage de porcs en engraissement. Journeés Recherche Porcine, n. 43, p. 199-204, 2011. Disponível em: <http://www.journees-rechercheporcine.com/texte/2011/environnement/e2f.pdf>

INMET - Instituto Nacional de Meteorologia. Estações e dados. Banco de dados meteorológicos para ensino e pesquisa. 2019. Disponível em: <http://www.inmet.gov.br/portal/index.php?r=bdmep/bdmep>.

ITO, M.; GUIMARÃES, D.; AMARAL, G. Impactos ambientais da suinocultura: desafios e oportunidades. Agroindústria, BNDES Setorial 44, p.125-156, 2016.

Disponível.

em: <https://web.bndes.gov.br/bib/jspui/bitstream/1408/9974/2/BS\%2044\%20Impactos\% 20ambientais\%20da\%20suinocultura_P.pdf>

LE BOEDEC, K. Sensitivity and specificity of normality tests and consequences on reference interval accuracy at small sample size: a computer-simulation study. Veterinary Clinical Pathology, v. 45, n. 4, p. 648-656, 2016. Disponível em: <onlinelibrary.wiley.com/doi/pdf/10.1111/vcp.12390>.

doi: $10.1111 / \mathrm{vcp} .12390$

MIOT, H. Avaliação da normalidade dos dados em estudos clínicos e experimentais. Jornal Vascular Brasileiro, v. 16, n. 2, p. 88-91, 2017. Disponível em:

$<$ https://www.jvascbras.org/article/10.1590/1677-5449.041117/pdf/jvb-16-2-88.pdf> doi: 10.1590/1677-5449.041117 
NASCIMENTO, D. C.; TIBANA, R. A.; MELO, G. F.; PRESTES, J. Testes de normalidade em análises estatísticas: Uma orientação para praticantes em ciências da saúde e atividade física. Revista Mackenzie de Educação Física e Esporte, v. 14, n. 2, p. 73-77, 2015. Disponível em: $<$ https://www.researchgate.net/publication/320310794>

NFACC - National Farm Animal Care Council . Code of Practice: For the care and handling of Pigs. ISBN 978-0-9936189-3-2 (electronic book text). 2014. 78p.

Disponível em: <https://www.nfacc.ca/pdfs/codes/pig_code_of_practice.pdf>

NUNES, M. L. A.; MIRANDA, K. O. S. Alternativas para a redução da emissão de gases de efeito estufa pela suinocultura. Revista Thesis, São Paulo, v. 4, n. 19, p. 48-62, 2013. Disponível em: <http://www.cantareira.br/thesis2/ed_19/art4.pdf>

PEEL, M. C.; FINLAYSON, B.L.; McMAHON, T.A. Updated world of the KöppenGeiger climate classification. Revista Hydrology and Earth System Sciences, v. 11 , n. 5, p. 1633-1644. 2007.

R Core Team. R: A language and environment for statistical computing. Versão 3.5.0. R Foundation for Statistical Computing, Vienna, Austria. 2018. Disponível em: $<$ https://www.R-project.org/>

ROBIN, P. Reference procedures for the measurement of gaseous emissions from livestock houses and storages of animal manure. Final Report, ADEME, FR, april, 2010. 260 p. (Contrat N. 0674C0018). Disponível em:

$<$ https://www.ademe.fr/sites/default/files/assets/documents/70548_final_report_lca_1 st-generation-biofuels_france.pdf>

SANTOS, T. C.; CARVALHO, C. C. S.; SILVA, G. C.; DINIZ, T. A.; SOARES, T. E.; MOREIRA, S. M.; CECON, P. R. Influência do ambiente térmico no comportamento e desempenho zootécnico de suínos. Revista de Ciências Agroveterinárias, v. 17, n. 2, p. 241-253. 2018. Disponível em: < http://www.revistas.udesc.br/index.php/agroveterinaria/article/view/9614/pdf> doi: 10.5965/223811711722018241 